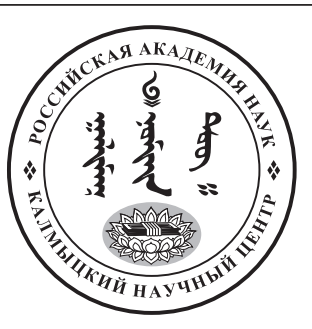

Published in the Russian Federation

Oriental Studies (Previous Name: Bulletin of the Kalmyk Institute

for Humanities of the Russian Academy of Sciences)

Has been issued as a journal since 2008

ISSN: 2619-0990; E-ISSN: 2619-1008

Vol. 14, Is. 1, pp. 103-114, 2021

Journal homepage: https://kigiran.elpub.ru

УДК / UDC 391; 37.01: 39

DOI: 10.22162/2619-0990-2021-53-1-103-114

\title{
Особенности национальной одежды алтайцев
}

\section{Эмма Васильевна Екеева, Николай Васильевич Екеев}

${ }^{1}$ Горно-Алтайский государственный университет (д. 1, ул. Ленкина, 649000 Горно-Алтайск, Российская Федерация); Научно-исследовательский институт алтаистики им. С. С. Суразакова (д. 6, ул. Социалистическая, 649000 Горно-Алтайск, Российская Федерация) кандидат педагогических наук, доцент; старший научный сотрудник (iD)0000-0002-4816-4341. E-mail: etno_ped@mail.ru

${ }^{2}$ Научно-исследовательский институт алтаистики им. С. С. Суразакова (д. 6, ул. Социалистическая, 649000 Горно-Алтайск, Российская Федерация) кандидат исторических наук, старший научный сотрудник, директор iD) 0000-0002-2372-7769. E-mail: n_kazat@mail.ru

(c) КалмНЦ РАН, 2021

(С) Екеева Э. В., Екеев Н. В., 2021

Аннотация. Введение. Основываясь на исследованиях отечественных этнографов и собственных полевых материалах, автор впервые рассматривает особенности национальной одежды алтайцев с указанием изменений, которым она подверглась в современный период. Основной целью исследования является выявление трансформации национальной одежды алтайцев, произошедшей в конце XX - начале XXI вв. Материалом для исследования послужили данные полевых экспедиций, проведенных в Усть-Канском, Шебалинском и других районах Республики Алтай в 2017-2019 гг. Материалы в основном собирались методами анкетирования и устного опроса местного населения вышеназванных районов Республики Алтай. Результаты. Автором рассмотрена мужская и женская одежда, которая представлена, прежде всего, разными видами верхней одежды: овчинные шубы некей тон (букв. 'шуба из шкуры с длинным, густым мехом'), акар тон (букв. 'шуба из шкуры с густым, коротким мехом'), кыпту тон (букв. 'шуба, отороченная матерчатой верхней выпушкой'), полушубок торток тон, безрукавки кӧгӱспек, халаты чекпен. Дано описание шапок (тӥлкё бычкак бӧрӥк, талбан бӧрӥк, киш бӧрӥк, болчок бӧрӥк), которые носили мужчины и женщины, и обуви из камусов животных

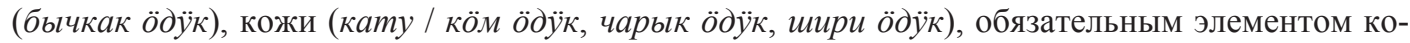
торой является загнутый вверх носок. Рассмотрена женская свадебная и праздничная одежда: платья с широкими рукавами, манжеты которых полностью закрывали кисти рук, украшались пуговицами, бусами, орнаментом и надевались под длиннополой шелковой безрукавкой. Показано отличие традиционной и стилизованной женской длиннополой безрукавки чегедек, 
надеваемой поверх платья невесты во время свадебной церемонии. Чегедек имеет символическое значение и отражает переход девушки в статус замужней женщины; в статье раскрыты особенности техники его пошива. Описана нижняя одежда мужчин: рубашка простого покроя чамча, которую носили чаще всего навыпуск, поверх брюк штан из шерстяных и других тканей. Bblводbl. Одежда алтайцев претерпела изменения, но некоторые многовековые традиции сохраняются и в наши дни, так, например, при пошиве женского наряда сохранились рукава уштуктар и «крылья» канаттар. Наряду с этим, следует отметить, что не соблюдаются традиции выбора цветов одежды в зависимости от возраста и пола человека, изменилось размещение декора в национальной одежде. Утрата этнических черт в национальной одежде связана с широким распространением покупных тканей и пошивом одежды на заказ.

Ключевые слова: алтайцы, традиции, культура, национальная одежда, верхняя и нижняя одежда, головной убор, обувь, классический тип одежды, стилизованная одежда

Благодарность. Исследование выполнено при финансовой поддержке Научно-исследовательского института алтаистики им. С. С. Суразакова в рамках научного проекта «Этнографический атлас Республики Алтай» (2019 г).

Для цитирования: Екеева Э. В., Екеев Н. В. Особенности национальной одежды алтайцев // Oriental Studies. T. 14. № 1. C. 103-114. DOI: 10.22162/2619-0990-2021-53-1-103-114

\title{
National Clothes of Altaians: Essential Features Revisited
}

\author{
Emma V. Ekeyeva ${ }^{1}$,Nikolay V. Ekeyev ${ }^{2}$
}

${ }^{1}$ Gorno-Altaisk State University (1, Lenkin St., Gorno-Altaisk 649000, Russian Federation); Surazakov Institute for Altaic Studies (6, Sotsialisticheskaya St., Gorno-Altaisk 649000, Russian Federation) Cand. Sc. (Pedagogy), Associate Professor; Senior Research Associate

iD 0000-0002-4816-4341. E-mail: etno_ped@mail.ru

${ }^{2}$ Surazakov Institute for Altaic Studies (6, Sotsialisticheskaya St., Gorno-Altaisk 649000, Russian Federation)

Cand. Sc. (History), Leading Senior Research Associate, Director

iD 0000-0002-2372-7769.E-mail:n_kazat@mail.ru

(C) KalmSC RAS, 2021

(C) Ekeyeva E. V., Ekeyev N. V., 2021

\begin{abstract}
Introduction. With reference to works by Russian ethnographers and collected field materials, the paper presents the first insight into specific features of Altaian traditional clothes and changes the latter undergo in the modern period. Goals. The work primarily seeks to reveal transformations of Altaian national garments in the late $20^{\text {th }}-$ early $21^{\text {st }}$ centuries. Materials. The study examines data from field expeditions to Ust-Kansky, Shebalinsky and other districts of the Altai Republic in 2017-2019. The research data collection methods included those of questionnaires and interviews among local communities of the mentioned districts of the region. Results. The paper highlights various aspects of men's and women's clothes represented mainly by outer garments, such as sheepskin coats, e.g., nekey ton (a sheepskin coat a with long thick fur), akar ton (a coat sheepskin with short thick fur), kyptu ton (a coat with fabric-trimmed upper elements), tortok ton (a short sheepskin coat), and also sleeveless jackets (kögÿspek) and national gowns (chekpen). The work

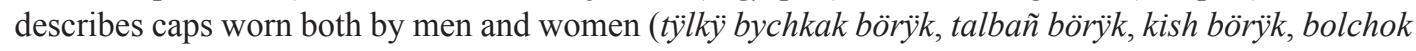
börÿk), shoes made of fur (skin) from animals' lower legs (bychkak ödÿk) or leather ones (katu/ köm $\ddot{o} d \ddot{y} k$, charyk ödÿk, shiri ödÿk) usually decorated with upright pointed toes. Special attention is paid to women's wedding and festal clothes, namely: dresses with wide sleeves and long cuffs that were to completely cover hands, the former decorated with buttons, beads, and ornaments to be worn under a full-length silk sleeveless jacket. The research explains differences between the classical and
\end{abstract}


contemporary conventionalized chegedek full-length sleeveless jackets worn by women over a special dress during wedding ceremonies. Chegedek communicates a symbolic message that a girl acquires the new status of a married woman. Some attention is given to men's undergarments, such as regular shirts (chamcha) mostly worn untucked with woolen trousers (shtan). Conclusions. The Altaian clothes have underwent certain changes but some centuries-old traditions survive till nowadays, e.g., women's dresses are distinguished by special sleeves (ushtuktar) and 'wings' (kanattar). However, it is noteworthy that the tradition of selecting colors for garments with due regard of age and sex is lost, and layout of decorative elements has also changed. The loss of ethnic features in national clothes results from the wide use of commercial cloths and services of tailor shops.

Keywords: Altaian people, traditions, culture, national clothes, outer garments, undergarments, headdress, shoes, classical type of clothes, stylized clothes

Acknowledgements. The reported study was funded by the Surazakov Institute for Altaic Studies, research project 'Ethnographic Atlas of the Altai Republic' (2019).

For citation: Ekeyeva E. V., Ekeyev N. V. National Clothes of Altaians: Essential Features Revisited. Oriental Studies. 2021. Vol. 14(1): 103-114. (In Russ.). DOI: 10.22162/2619-0990-2021-53-1-103114

\section{है}

\section{Введение}

Национальная одежда как один из элементов материальной культуры народа вызывает большой интерес у исследователей. Наиболее ранними источниками об одежде народов Горного Алтая являются археологические материалы, летописи, сохранившиеся со времен правления династии Тан, а также исторические документы середины XVIII в., когда алтайцы входили в состав Джунгарии [Бичурин 1851].

Одежда алтайцев, а также различия в одежде в зависимости от их возраста, пола и семейного положения, описаны в трудах Г. И. Спасского, К. Ф. Ледебура, А. А. Бунге, В. В. Радлова, С. П. Швецова [Спасский 2004; Ледебур 2004; Бунге 2004; Радлов 1989; Швецов 1900] и других исследователей XIX-XX вв.

Л. П. Потаповым в статье «Одежда алтайцев», вышедшей в сборнике Музея археологии и этнографии, дан подробный анализ одежды алтайцев, а также украшений и причесок с разделением их по полу, возрасту и этнической группе [Потапов 1951].

В работе Н. И. Шатиновой «Семья у алтайцев» рассмотрена семантика одежды, надеваемой алтайцами на свадьбу и похороны [Шатинова 1981]. Значение и смысловая нагрузка накосных украшений алтаек изучены Н. И. Клюевой [Клюева 1988].
В коллективной монографии «Традиционное мировоззрение тюрков Южной Сибири. Пространство и время. Вещный мир» рассмотрено значение алтайской одежды и её элементов [Традиционное мировоззрение 1988]. Авторами дана классификация и систематизация одежды, была сделана попытка соотнести их с мировоззрением алтайцев, проведено сравнение с традиционной одеждой других народов.

В книге «Алтайский национальный костюм» представлены сценические костюмы, даны краткие сведения о традиционном костюме алтайцев, в неё включены цветные иллюстрации, выполненные современными художниками [Алтайский национальный $1990]$.

Н. А. Тадиной в монографии «Алтайская свадебная обрядность (XIX-XX вв.)», на основе полевых материалов и большого круга источников, была предпринята попытка комплексного исследования алтайской свадьбы. В числе прочих рассмотренных вопросов отдельный параграф посвящен одежде, украшениям и прическам по половозрастному признаку [Тадина 1995].

Об особенностях национальной алтайской одежды в настоящее время написано много статей, изданных в республиканских газетах, в сборниках конференций. Значимость для нашей работы представляют 
монография «Тюркские народы Сибири» [Тюркские народы 2006: 409-412] и статьи Б. Ю. Кичековой, опубликованные в научном журнале «Билим» в 2008-2010 гг. [Кичекова 2008; Кичекова 2009; Кичекова 2010].

Из последних научных трудов данного института следует выделить коллективные монографии «Алтайцы» и «Культура населения Алтая эпохи древности и средневековья: проблемы реконструкции и сопоставления с традиционной культурой алтайцев», изданные в 2014 и 2018 гг. [Алтайцы 2014; Эбель, Трифанова, Константинов 2018]. Однако нет научного издания, в котором была бы рассмотрена трансформация национальной одежды алтайцев. Поэтому целью данной статьи является изучение одежды алтайцев с указанием изменений, которым она подверглась в современный период.

\section{Материалы и методы}

Автор статьи опирался на опубликованные источники и на полевой материал, собранный в течение 2017-2019 гг. в селах Республики Алтай. В исследовании использован метод историзма, позволяющий рассматривать изменение национальной одежды алтайцев в XIX - начале XXI вв. Также применяются методы полевых исследований, сравнения и описания.

\section{Особенности национальной одежды алтайцев}

Одежда является одним из маркеров материальной культуры народов, в ней их история, вековые традиции, моральные нормы.

Одежда алтайцев, как и раньше, соответствует различным бытовым ситуациям, поэтому подразделяется на повседневную и праздничную, а в зависимости от климатических условий делится на зимнюю и летнюю, от возраста её обладателя - на одежду детей и подростков, молодежи, взрослых и пожилых людей, а от пола людей на мужскую и женскую.

Верхней плечевой одеждой мужчин, как и женщин, является шуба тон, которую шьют из овечьих шкур белого цвета. Крой у мужских и женских шуб одинаков, без талии, свободно расширяющийся книзу, с запахом слева направо так, что левая пола перекрывает правую полу и вырезана ступенчато. Воротник шубы, как правило, делают из лисьего меха. Нагрудная часть ёмюр $(\ddot{о м} \ddot{y p})^{1}$ в мужских и женских шубах выкраивается почти одинаково, но отличается по размерам и оформлению орнаментов.

Рисунок нагрудной части мужской шубы состоит из ромбов и звездочек. Красиво вышитая нагрудная часть является и своего рода оберегом от сглаза. Рукава ден (јен) мужской шубы, широкие от плеча, в запястье резко сужаются и заканчиваются манжетой уштук прямоугольной формы. На концах рукавов, внизу по подолу и вдоль левой полы нашивают широкую кайму из бархата или простой материи, а также украшают цветной вышивкой, считавшейся оберегом и символом плодородия и богатства. Раньше нашивали кайму из телячьей или жеребячьей кожи [Кичекова 2008: 127-128; ПМА: инф. 1].

Овчинную шубу так же, как шубу из шкуры с длинным, густым мехом (некей тон) и шубу из шкуры с густым, коротким мехом (акар тон), носили только в холодное время года, а весной и осенью - шубу, обшитую бархатом, шёлком или другой матерчатой верхней окантовкой (кыпту тон), или полушубок (торток тон).

Утрачена техника пошива шуб из собачьих, медвежьих и оленьих шкур дьаакь тон (јаакьл тон), из зимней, весенней и осенней шкуры косули каба тон, тёёч тон (тӧӧчи тон), кер тон, из шкуры с коротким и редким мехом (тарбыл тон) или из шкуры без меха дьаргак тон (јаргак тон). Раньше шуба была приспособлена к верховой езде в холодное время года, так как она была просторной и с длинными полами, что позволяло укрыть ими ноги, а её широкий рукав использовался для транспортировки маленького ребёнка во время перекочевок. Шубу раньше носили и в тёплое время года. Летом, в жаркую погоду, шубу спускали с плеч, и верхняя часть её опускалась на пояс, а в дождливый день шубу выворачивали мехом наружу, чтобы предохранить её от сырости [ПМА: инф. 1; Эбель, Трифанова, Константинов 2018].

До настоящего времени в гардеробе алтайских мужчин сохранился летний вид верхней одежды - чекпен, представляющий собой широкий халат на подкладке.

1 Здесь и далее при описании видов одежды вначале приводится русское написание, в скобках - алтайское. 
Он шьётся из дорогого материала (предпочтение отдаётся бархату тёмного цвета) с широкими рукавами, без воротника, с боковыми разрезами. Спинку халата украшают орнаментом и кисточкой. Раньше его шили из хорошего сукна, нанки или дабы на шелковой или сатиновой подкладке, с большим цветными плисовым или суконным отложным воротником.

Современные жители Горно-Алтайска заказывают в ателье национальную одежду, например, мужской халат с крыльями. Халат, как и овчинная шуба, стал больше праздничной одеждой мужчин [ПМА: инф. 2].

Легкой верхней одеждой мужчин является безрукавка кёгюспек (кӧгӱспек), дьендьок (јенјок). Безрукавку носят как в повседневной жизни, так и в праздники. Безрукавка для каждодневного ношения шьётся из бархата или шерстяных тканей, с карманами и разрезами по бокам. Праздничный вариант безрукавки, например, как элемент свадебного наряда жениха, шьётся из бархата или парчи. На свадебном костюме жениха используют родовую тамгу танма. Родовой тамгой украшают также безрукавки, носимые в праздники [ПМА: инф. 1; ПМА: инф. 3].

В настоящее время мужчины и женщины стали носить безрукавки, сшитые из войлока из овечьей шерсти. Предпочтение отдаётся шерсти белого цвета. Войлочные безрукавки украшают орнаментом, комбинируют с мехом норки, на них накладывают рисунок. Их шьют с карманами и без них. Войлочная безрукавка стала как повседневной, так и праздничной одеждой современных алтайцев.

К нижней плечевой мужской одежде относится рубашка чамча, которая имеет простой покрой, шьётся из разной ткани, например, на праздники или свадьбу её шьют из шёлковой ткани со стоячим воротником и с зауженными рукавами у запястья. Иногда стягивают рубашку поясом. Рубашки также носят навыпуск, поверх брюк, часто без пояса. Мужская рубаха в прошлом по крою была распашной, с косым или невысоким стоячим воротником, открытой спереди и с длинными широкими рукавами. Полы рубахи застегивались на одну пуговицу у подбородка, а на воротнике пуговица не застегивалась. Рубахи отличались мате- риалом в зависимости от социального статуса мужчины [ПМА: инф. 2].

Нижняя мужская одежда состоит из

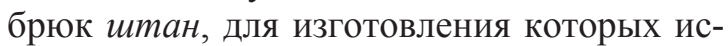
пользуют шерстяные и другие ткани. Чаще всего мужчины носят брюки фабричного производства.

Aксессуары. Важной частью мужской одежды, как и женской, является пояс кур. В качестве пояса используется отрез материи длиной 3-4 метра, которым подпоясываются два раза; его концы подтыкаются спереди и свешиваются вниз. В зависимости от бытовых ситуаций используется ткань разных цветов и качества. На праздниках, например, во время сватовства, на свадьбе сватам надевают пояс из дорогих тканей. Предпочтение отдается поясам из простых материалов (ситец, бязь и т. п.) нежели шёлковым, которые быстро распускаются.

Мужчины надевают кожаные пояса кайьиш кур, к которым прикрепляется нож в кожаных или деревянных ножнах. Если раньше кожаный пояс украшали бронзовыми бляшками, прикрепляли к нему патронташ и мешочек для пуль, огниво в кожаной оправе с бронзовой отделкой, то в настоящее время на них наносится орнаментальный рисунок.

Мужчины зимой носят шапку из лисьих камусов - тюлкю бычкак бёрюк (тӥлкӥ бычкак бӧрӥк), ставшую в настоящее время самой востребованной. Внутренний слой данной шапки шьётся из шкурки белого ягнёнка. Край этой шапки так же, как и у всех шапок, сшиваемых из камусов диких животных, отделывается парчой чинмери / кюре (чинмери / кӱре), оторачивается узкой полоской меха выдры камду, а к её макушке пришивается кисть из цветных ниток чачак, длиной до плеч, с помощью короткой низки бус [ПМА: инф. 4].

Среди современных мужчин-алтайцев стали востребованы шапки, сшитые из хвостиков и шкур норки чёрного цвета, края которых отделаны парчой и узкой полоской меха выдры норканын куйруктарынан, терезинен эткен бёрюктер (норканын куйруктарынан, терезинен эткен бӧрӥктер). Эти шапки чаще всего шьют жениху на свадьбу.

Мужчины зимой носят также шапку круглой формы болчок бёрюк (болчок бӧрӥк), которую шьют из разных материалов, чаще всего из мерлушки - мехом 
вниз, сверху нашивают тёмный или цветной однотонный материал. Шапку кроят из четырёх деталей, суживающихся к макушке. Край шапки также обрамляется парчой и узкой полоской меха выдры, а к макушке пришивают кисть из цветных ниток [ПМА: инф. 4; ПМА: инф. 6]. Есть и бюджетный вариант этого головного убора - шапка, отделанная искусственным мехом [ПМА: инф. 7]. Мужская шапка круглой формы, которую носят весной и осенью, шьётся также из войлока кийис бёрюк (кийис бӧрӥк), сделанного из овечьей шерсти белого или чёрного цвета.

Крайне редко в настоящее время можно увидеть мужчин в конусообразной шапке из чёрной мерлушки сююрю кураан бёрюк (сёурй кураан бӧрӥк), похожей на высокий гребень, сужающийся сзади и без разреза, выделанной из шкурки ягнёнка грубошерстной породы овец. Сзади к шапке прикрепляют широкие шёлковые ленты (длиной 72 см, шириной 6 см), свисающие по спине [ПМА: инф. 4; ПМА: инф. 6]. Чаще всего эта шапка сегодня является одним из элементов сценического костюма алтайских артистов.

Для мужчин раньше шили войлочную шапку с длинными «ушками» и слегка вытянутой макушкой калбан бёрюк (калбан бӧрӥк), носимой ими в холодное время года [ПМА: инф. 8].

В летний период мужчины носили тюбетейку такыйа из льна, бархата, плюша, шёлка.

\section{Женская одежда}

Зимней верхней одеждой алтайских женщин является овчинная шуба (тере тон), которая в целом не отличается от мужской и шьётся свободным кроем. Овчинную шубу называют также дьакалу акар тон (јакалу акар тон) [Загадки 2010: 19]. Само название говорит, что шуба сшита из шкуры с коротким густым ворсом и с воротом.

Женские шубы отличаются от мужских более длинными полами, более красочно оформленной нагрудной частью и манжетами. Нагрудная часть женской шубы, в отличие от мужской, выкраивается в виде четырехугольного выступа и украшается вышивкой, состоящей из цветочного рисунка. Рукава женской шубы длинные. Манжеты женских шуб в настоящее время чаще всего выкраиваются прямоугольной формы, украшаются вышивкой, отделываются мехом. Также встречаются шубы с манжетами, как и традиционные, в форме конских копыт. Выступы, доходящие до кончиков пальцев, закрывают руки, так как алтайской женщине, согласно обычаям, не полагалось их показывать родственникам мужа. Кроме того, такие манжеты лучше защищают от мороза. Вышивка манжет состоит из ромбических и других узоров разных цветов.

На женской шубе широкая чёрная полоса обозначает дорогу жизни, а название узкой полосы курчынылы дьоль (курчунын joлbl) на русский язык переводится как «оберег» [ПМА: инф. 1].

Шубе дьакалу акар тон (јакалу акар тон) посвящена песня, в которой поётся:

\author{
Алтынн-мӧнӥн топчылу \\ Акар тоннын ӧнжигин. \\ Алтай келин ортодо \\ Тай-јенемнин јаражын. \\ Јергелей топчы тагарда \\ Јелмер тоннын ӧнжӥгин! \\ Јетен келин ортодо \\ Јенейектин јаражын! \\ [ПМА: инф. 1]
}

\author{
Пуговицы серебристо-золотые \\ Блестят на шубе акар тон \\ Среди алтайских невест. \\ Наша тётя-сноха в акар тоне красива. \\ В ряд, когда пуговицы пришили, \\ Лохматая шуба так красива! \\ Среди сорока невест \\ Сноха наша так красива! \\ [Перевод Э. В. Екеевой]
}

Легкая верхняя женская одежда представлена длиннополой безрукавкой чегедек, надеваемой поверх платья невесты во время свадебной церемонии, имеющей символическое значение и отражающей переход девушки в статус замужней женщины. Длиннополая безрукавка шьётся матерью жениха, его сестрами, тётями, так как в их семью девушка приходит, чтобы стать женой, матерью - продолжательницей рода [Тохтонова 2004: 4].

Современные длиннополые безрукавки чегедектер шьются в классическом и стилизованном стиле из бархата или шёлка си- 
него, голубого и красного цветов. Традиционная длиннополая безрукавка украшалась кантами из цветных полос ткани, на которые нашиты скрученные в косички нитки, напоминающие цвет радуги солонын ӧни. От ворота до линии груди по обеим полочкам на кант нашивались перламутровые пуговицы тана, на её левой поле раньше пришивались две большие китайские красные пуговицы куйка как чисто декоративный элемент.

Воротник длиннополой безрукавки выкраивался отдельно, украшался узорами и пристегивался к ней. Узоры воротника, украшаемого низками бус, имели символические знаки течения реки, жизни, солнца, луны, звезд.

Примечательным элементом длиннополой безрукавки являются её плечи, похожие на крылья птиц. Чтобы «крылья» держали форму, раньше их обмазывали мукой, а сейчас используют для этого плотные ткани, в которые вшиваются сетчатые вкладки. Подобная форма «крыльев» информантами объясняется по-разному. Так, одни считают, что это делается для красоты, а другие полагают, что подобные «крыльям» плечи длиннополой безрукавки обозначают горы Алтая [ПМА: инф. 2; ПМА: инф. 3].

Талия классической длиннополой безрукавки в отличие от стилизованной безрукавки располагается на бедрах. На стилизованной длиннополой безрукавке отсутствует металлическая подвеска бельдӱуш, которую носили на левом боку и на которую раньше навешивали кисет, огниво, игольницу и мешочки с пуповинами детей байры. Вместо металлической подвески в настоящее время пришиваются имитации игольницы и пуповин детей.

На стилизованной длиннополой безрукавке современных жительниц Горного Алтая появились орнаменты, которые наклеиваются, нашиваются или вырезаются. Следует отметить, что наблюдается чрезмерное использование орнаментального рисунка на современной длиннополой безрукавке, что не было характерно для нее в прошлом. Чаще всего мастерицами используются готовые орнаменты, привезённые из других стран.

Символика, используемая при орнаментировке женской длиннополой безрукавки и другой одежды:
- кулдьа (кулја) - символ богатства, изобилия, благополучия;

- чычрана (облепиха) вышивается только на груди (ёмюр (ӧмӥр)), обозначает живительные силы и урожайность;

- кёстёр (кӧстӧр) вышиваются на ӧмӥр детских шуб или шапках;

- кыззыл каадыbl (кыззыл каајы), калбак каaдbы (калбак каајы) (солярные круги) - знаки, накладываемые вышивкой на манжеты;

- кёс чечек (кӧс чечек) - на окантовке шубы (тонын кыйузына (тоннынг кыйузына));

- ёзёктю кёстёр (ӧзӧктӥ кӧстӧр) вышиваются на женской одежде;

- алака - знаки, символизирующие связь поколений, вышиваются на мужской и женской одежде [Загадки 2010: 24].

Современная длиннополая безрукавка, в отличие от старинных, имеет застежку в виде крючков и пуговиц. Её носят, как и раньше, и зимой, и летом - как нараспашку, так и подпоясанной, а также поверх любой одежды. Чегедек нередко надевают поверх европейской одежды.

Верхней одеждой молодых девушек является халат чекпен, который по покрою одинаковый с мужским. Его шьют из тканей синего и голубого цвета, носят как в повседневной жизни, так и в праздники. Современный халат застегивается на пуговицы, а раньше он подпоясывался кушаком.

Нижняя одежда женщин состоит из платья с широкими руками. Платье надевают под длиннополой безрукавкой. Оно шьётся из шёлка, украшается пуговицами, бусами, орнаментом, является свадебной и праздничной одеждой. Особую форму имеют манжеты рукавов платья. Они полностью закрывают кисти рук. У алтайцев до сих пор считается неприличным оголять кисти рук, как, собственно, и другие части тела.

Нижнюю одежду алтайских женщин ранее составляли рубаха и шаровары, схожие с мужскими. Женщины постепенно перешли к одежде, состоящей из широкой юбки, собранной в складки, блузки и платка [Кичекова 2008; Кичекова 2009].

Головныле уборы. Женские шапки представлены меховыми, тканевыми и войлочными видами. Женщины, как и мужчины, зимой носят головной убор из лисьих ка-

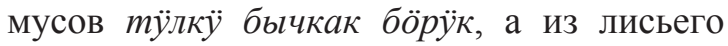


меха - шапку с длинными вытянутыми «ушками» талбан бӧрӥк.

Парадной является шапка, отороченная собольим мехом киш бӧрӥк. Ее покрой очень сложен, данный головной убор состоит из четырёх клиньев неправильной формы, сшитых особым образом.

Зимние женские шапки бывают круглой (болчок бӧрӥк) и конусообразной (сӥурй бӧрӥк) форм, изготавливаются они из чёрной мерлушки. Шапку круглой формы сверху покрывают бархатом, её край обшивают парчой и полоской меха выдры, к макушке пришивают кисточку из шёлковых нитей.

Конусообразная шапка выкраивается с расширенным основанием и закругленным углом, сшиваются впереди и сзади околыши, делается из красной ткани и овальной формы днище, пришиваются сзади две шёлковые ленты [ПМА: инф. 4].

У женщин спросом пользовалась конусообразная шапка, внутренний слой которой шьётся из шкурки белого ягнёнка, а наружная часть состоит из 6 клиньев, выкроенных из бархата (сӥурй бӧрик). Она обшивается также парчой любого цвета и украшается вышивкой-гладью, узорами в виде снежинок. Ниже пришивается тесьма или полоска блестящей парчи, что обозначает разноцветие Алтая, красоту его растительного мира. Затем пришивается полоска меха выдры (камду), которая говорит о богатстве животного мира Алтая. Иногда вместо меха выдры пришивают полоску из шкурки ягнёнка коричневого цвета, так как считается, что ягнёнок является животным

\author{
Элик бычкак ӧдйкти \\ Энем кӧктӧгӧн кеп эмей. \\ Эки ууль келди деп, \\ Энем јыргап бу турбай. \\ Ан бычкак ӧдӥкти \\ Адам тапкан кеп эмей. \\ Алты ууль келди деп \\ Адам јыргап отурбай. \\ [ПМА: инф. 12].
}

В настоящее время некоторые алтайцы носят стилизованную обувь, похожую на унты, при изготовлении которой используется кожа и косульи или оленьи камусы. В отличие от традиционной кожаной обуви, передняя часть голенищ этой обуви с «тёплым дыханием» (јылу тумчукту мал) [ПМА: инф. 4].

В женский гардероб входят и стилизо-

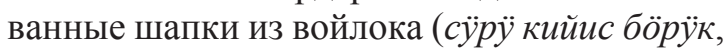
болчок кийис бӧрӥк), украшенные орнаментом.

Головной убор женщин также представлен платком арчуул. Женщины носят платки разного качества, среди которых самыми популярными являются шёлковые и шерстяные.

Мужская и жсенская обувь. Обувь ӧдик алтайцев подразделяется на виды: обувь из камусов животных (бычкак ӧдйк), кожаная обувь (кату / кӧм ӧдӥк), сапоги с кожаным носком, ступней и суконными голенищами (чарык ӧдёк) и обувь из дублёной кожи (чири ӧдёк). Обязательным и красивым их элементом является носок, который загнут вверх.

Традиционная меховая обувь изготавливалась из камусов косули, кабарги, оленя, овец и коз. На пошив носка и передней части обуви шли самые длинные лапки. После выведения носка накладывались и соединялись боковые и задние части. Затем все выворачивалось, и начиналась выделка кожи со снятием мездры. Сшитая таким образом обувь была прочной, и швы на ней не расходились. На голенище такая обувь перетягивалась ремешком. Обувь этого же вида только без ремешков называется башпак. Её носили с войлочными чулками ук [ПМА: инф. 5].

Обуви, сшитой из камусов косули, посвящена песня, где есть следующие строки:

Из косульих камусов обувь,

Матерью, сшитая одежда.

Два сына пришли, говоря,

Мать празднует [вот так].

Из оленьих камусов обувь,

Отцом добытая одежда.

Шесть сыновей пришли, говоря,

Отец, празднуя, сидит.

[Перевод Э. В. Екеевой]

сшита из косульих или оленьих камусов. На ней также имеется пятка ак-буm, изготовленная из войлока и кожи и украшенная орнаментом. Такую обувь ранее носили с кожаными чулками тере ук [ПМА: инф. 10]. 
Кожаная обувь (кӧм / кату ӧдйк) в настоящее время изготавливается из кожи фабричного производства. Остались редкие умельцы, умеющие выделывать кожу из шкур крупного рогатого скота и умеющие шить из неё обувь. Между швами для уплотнения кожи накладывается «скыт» из кожи цвета обуви. Такая обувь украшается орнаментами из светлой или красной кожи и другим тиснением [ПМА: инф. 9].

При шитье как меховой, так и кожаной обуви в настоящее время используют резиновую подошву. Новшеством в шитье женской меховой и кожаной обуви стало наличие каблука. В стилизованной обуви, в отличие от традиционной, практически исчез заостренный, поднятый к верху носок, который стал закругленным. Характерной особенностью современной стилизованной обуви алтайцев является стремление частично сохранить национальный колорит традиционной обуви.

\section{Детская одежда}

Традиционная детская одежда практически ничем не отличалась от взрослой. Мальчики носили такие же, как и у мужчин, брюки, рубашку, легкий халат чекпен, шубу из овечьих шкур тере тон и молодых ягнят - корокой тон.

Шубы детей, как и взрослых, имели запа́х слева направо таким образом, чтобы левая половина перекрывала правую половину. Но девичьи шубы отличались от мальчишечьих более красочным оформлением передней верхней планки ӧмӥр и манжетами. Красиво вышитый ӧмӥр является своего рода оберегом от сглаза. Крайняя верхняя вертикальная линия служила кармашком. Воротник шубы специально изготавливался небольшого размера, чтобы не закрывать красоту ӧмӥр. Манжеты девичьих шуб выкраивали заостренными к середине, выступы доходят до кончиков пальцев. Такие манжеты лучше защищают от мороза. Ӧмӥр мальчика вышит скромнее, манжеты не заострены.

Для девочек шили шубки и безрукавки из овечьих и лисьих шкур [ПМА: инф. 3].

Некоторое отличие наблюдается лишь в отделке предметов одежды. Детская одежда изготавливалась более нарядной, чем взрослая; для неё использовались более яркие цвета тканей. На одежде детей до сих пор встречается оберег шалтрак [Кичекова 2010: 127-128; ПМА: инф. 2].
Головные уборы детей изготавливались также из меха, войлока, бархата, шёлка. Зимние шапки детей и в настоящее время шьют из шкур особо ценных зверей, с пришитыми сзади двумя хвостами јалалу бӧрӱк. Девочки носили из шкур рыжей лисы и бархата шапку-ушанку кулакту бӧрӥк. На мальчиках можно увидеть и сегодня белые войлочные шапки калбан бӧрӥк, украшенные орнаментом. В летний период мальчики носили тюбетейку такыйа из бархата, плюша и хлопчатобумажной ткани, а девочки - шёлковые и парчовые шапочки круглой формы. Дети носили ранее шапки, покрытые бархатом килин бӧрӥк, разукрашенные в соответствии с принадлежностью к мужскому или женскому полу.

Маленькие дети носили войлочную обувь. Детям до 2 лет обувь, подошва которой сделана из кожи, изготавливалась из шкур ягнёнка или козлёнка, мехом наизнанку. И сегодня востребована детская меховая обувь бычкак ӧдик, которую шьют аналогично меховой обуви для взрослых [ПМА: инф. 6].

Современные алтайские дети также носят кожаную обувь с поднятым носком, которая украшена орнаментом-аппликацией из кожи контрастного цвета [ПМА: инф. 11].

\section{Заключение}

Одежда алтайцев претерпела изменения, но некоторые многовековые традиции, архаические представления и в наши дни сохраняются. Это касается, прежде всего, головных уборов, сшитых из лисьих камусов, а также верхней одежды алтайцев, в частности женской длиннополой безрукавки. Наряду с этим следует отметить, что сегодня не соблюдаются традиции выбора цветов одежды в зависимости от возраста и пола; появились современные детали, например, накладные карманы, чрезмерно используют орнаменты, чаще всего покупные. Нет мастеров, использующих самодельные нитки, сделанные из сухожилий коровы или косули. Раньше алтайцы при забое скота брали сухожилия с ног и размягчали, ударяя по ним колотушкой токпок. Затем их расчёсывали, а когда сухожилия распадались на множество мелких волокон, их свивали в тонкие крепкие нитки. Такими нитками шили верхнюю одежду и обувь. Для шитья 
использовались два заостренных конца одной нити. Затем волокна этой нитки немного раскручивали возле шва и пропускали в образовавшуюся петлю конец второй нити. Петля вновь закручивалась, и первая нить протягивалась в обратном направлении, пока конец второй нити не показывался на противоположной стороне шва. После чего обе нити затягивались за концы в разные стороны. Такой шов был очень крепким и не пропускал влаги. Сейчас, конечно, одежду шьют нитями фабричного производства [ПМА: инф. 4; ПМА: инф. 11].

Сегодня практически забыты способы выделки овчины, обработки кожи, мало людей, умеющих шить верхнюю одежду из кожи. Раньше шкуры обрабатывались специальным образом в зависимости от назначения. Сначала её разминали, затем отмачивали, чтобы размягчить. Подготовленная таким образом шкура шла на изготовление головных уборов, шуб, обуви. Для разных

\section{Полевой материал автора}

ПМА: инф. 1 - информант Аладякова Римма Доруковна, 1961 г. р., запись в с. Мендур-Соккон Республики Алтай, 2019 г.

ПМА: инф. 2 - информант Боконокова Анжелика Николаевна, 1974 г. р., запись в г. Горно-Алтайск Республики Алтай, 2019 г.

ПМА: инф. 3 - информант Кульдина Светлана Мартыновна, 1952 г. р., запись в с. Усть-Кан Республики Алтай, 2019 г.

ПМА: инф. 4 - информант Ойношева Валентина Адыровна, 1939 г. р., запись в с. БешОзёк Республики Алтай, 2017-2019 г.

ПМА: инф. 5 - информант Елекова Тамара Акчаевна, 1956 г. р., запись в с. Яконур Республики Алтай, 2019 г.

ПМА: инф. 6 - информант Таркрашева Нина Андреевна, 1939 г. р., запись в с. Шаргайта Республики Алтай, 2019 г.

\section{Author's Field Data}

Informant: Alena N. Erusheva, b. 1969. Rec. in Shebalino (Altai Republic, Russia), 2019. (In Russ. and Alt.)

Informant: Altynay I. Meshkeeva, b. 1972. Rec. in Saratan (Altai Republic, Russia), 2019. (In Russ. and Alt.)

Informant: Anzhelika N. Bokonokova, b. 1974. Rec. in Gorno-Altaysk (Altai Republic, Russia), 2019. (In Russ. and Alt.) шкур технологии обработки различались. Например, для размягчения овечьих шкур использовали сквашенное молоко чеген, для шкур коров и лошадей - специальный состав из воды, муки, соли, извести, а для шкур пушных зверей - чай [ПМА: инф. 8].

Традиционная алтайская одежда сегодня многими алтайцами шьётся на заказ. Данное обстоятельство можно объяснить тем, что в семьях утрачены навыки шитья традиционной одежды, а также в связи с трудоемким процессом, поэтому проще приобрести готовую одежду.

Национальную одежду повседневно носят алтайцы, живущие в сельской местности. Городские алтайцы полный традиционный костюм надевают во время семейных праздников - койу кӧчӧ (празднование первого года жизни ребёнка), свадеб, национальных - Эл-Ойын (Народные игры), Чага-Байрам (Новый год), Курултай сказителей и т. д.

ПМА: инф. 7 - информант Боянкина Динаида Александровна, 1957 г. р., запись в с. Шаргайта Республики Алтай, 2019 г.

ПМА: инф. 8 - информант Ерушева Алена Николаевна, 1969 г. р., запись в с. Шебалино Республики Алтай, 2019 г.

ПМА: инф. 9 - информант Аилдашев Николай Диргалович, 1959 г. р., запись в с. Боочи Республики Алтай, 2019 г.

ПМА: инф. 10 - информант Мешкеева Алтынай Исаковна, 1972 г. р., запись в с. Саратан Республики Алтай, 2019 г.

ПМА: инф. 11 - информант Санашев Марат Владимирович, 1962 г. р., запись в с. БешОзёк Республики Алтай, 2019 г.

ПМА: инф. 12 - информант Кудачинова Людмила Боробалановна, 1962 г. р., запись в с. Кокоря Республики Алтай, 2019 г.

Informant: Dinaida A. Boyankina, b. 1957. Rec. in Shargayta (Altai Republic, Russia), 2019. (In Russ. and Alt.)

Informant: Lyudmila B. Kudachinova, b. 1962. Rec. in Kokorya (Altai Republic, Russia), 2019. (In Russ. and Alt.)

Informant: Marat V. Sanashev, b. 1962. Rec. in Besh-Ozek (Altai Republic, Russia), 2019. (In Russ. and Alt.) 
Informant: Nikolay D. Aildashev, b. 1959. Rec. in Boochi (Altai Republic, Russia), 2019. (In Russ. and Alt.)

Informant: Nina A. Tarkrasheva, b. 1939. Rec. in Shargayta (Altai Republic, Russia), 2019. (In Russ. and Alt.)

Informant: Rimma D. Aladyakova, b. 1961. Rec. in Mendur-Sokkon (Altai Republic, Russia), 2019. (In Russ. and Alt.)

\section{Литература}

Алтайский национальный 1990 - Алтайский национальный костюм / сост. Е. П. Зайцева. Горно-Алтайск: Горно-Алт. отд. Алтайского кн. изд-ва, 1990.96 с.

Алтайцы 2014 - Алтайцы: Этническая история. Традиционная культура. Современное развитие / редколл.: Н. В. Екеев (отв. ред.), Н. М. Екеева, Э. В. Енчинов; НИИ алтаистики им. С. С. Суразакова. Горно-Алтайск: ООО «Горно-Алтайская типография», 2014. 464 с. 3 цвет. вкл.

Бичурин 1851 - Бичурин Н. Я. Собрание сведений о народах, обитавших в Средней Азии в древние времена. Ч. І. СПб.: Тип. военно-учебных заведений, 1851. 484 с.

Бунге 2004 - Бунге А. Путешествие по восточной части Алтайских гор // Слово об Алтае. Книга III. Часть I. Землеведение. Флора и фауна. Этнография. Религия. История / сост. Б. Бедюров. Горно-Алтайск: Юч-Сюмер-Белуха, 2004. С. 241-369.

Загадки 2010 - Загадки национальной одежды алтайцев / сост. Т. К. Бабрашева, А. Н. Боконокова. Горно-Алтайск: Энчи, 2010. 56 с.

Ледебур 2004 - Ледебур К. Ф. Путешествие по алтайским горам и предгорьям Алтая // Слово об Алтае / сост. Б. Бедюров. Кн. ІІІ. Горно-Алтайск: Юч-Сюмер-Белуха, 2004. C. $59-240$.

Кичекова 2008 - Кичекова Б. Ю. Традиционная одежда алтайцев // Билим. № 4 / отв. ред. А. Н. Майзина. Горно-Алтайск: ГНУ PA «Научно-исследовательский институт алтаистики им. С. С. Суразакова», 2008. С. $165-172$.

Кичекова 2009 - Кичекова Б. Ю. Изучение алтайской традиционной одежды и декоративно-прикладного искусства // Билим. № 5. Горно-Алтайск: ГНУ РА «Научно-исследовательский институт алтаистики им. С. С. Суразакова», 2009. С. 126-130.

Кичекова 2010 - Кичекова Б. Ю. Изучение алтайской традиционной одежды и декора-
Informant: Svetlana M. Kuldina, b. 1952. Rec. in Ust-Kan (Altai Republic, Russia), 2019. (In Russ. and Alt.)

Informant: Tamara A. Elekova, b. 1956. Rec. in Yakonur (Altai Republic, Russia), 2019. (In Russ. and Alt.)

Informant: Valentina A. Oynosheva, b. 1939. Rec. in Besh-Ozek (Altai Republic, Russia), 20172019. (In Russ. and Alt.)

тивно-прикладного искусства // Билим. № 6. Научный журнал. Горно-Алтайск: ГНУ РА «Научно-исследовательский институт алтаистики им. С. С. Суразакова», 2010. С. 126130.

Клюева 1988 - Клюева Н. И. Накосные украшения у сибирских народов // Материальная и духовная культура народов Сибири. Сб. Музея антропологии и этнографии. T. XLII. Л.: Наука, 1988. С. 105-128.

Потапов 1951 - Потапов Л. П. Одежда алтайцев // Сб. Музея антропологии и этнографии. Вып.13. М.; Л.: Изд-во АН СССР, 1951. C. 5-59.

Спасский 2004 - Спасский Г. Телеуты, или Белые калмыки // Слово об Алтае / сост. Б. Бедюров. Кн. III. Ч. І. Горно-Алтайск: Юч-Сюмер - Белуха, 2004. С. 33-42.

Радлов 1989 - Радлов В. В. Из Сибири. Страницы дневника. М.: Наука, 1989. 749 с.

Тадина 1995 - Тадина Н. А. Алтайская свадебная обрядность (XIX-XX вв.). Горно-Алтайск: Юч-Сюмер, 1995. 207 с.

Тохтонова 2004 - Тохтонова М. М. Традиции женской одежды // Ажуда. 2004. № 1. С. 4-6.

Тюркские народы 2006 - Тюркские народы Сибири / отв. ред. Д. А. Функ, Н. А. Томилов; Ин-т этнологии и антропологии им. Н. Н. Миклухо-Маклая РАН; Омский филиал Института археологии и этнографии СО РАН. М.: Наука, 2006. 678 с.

Традиционное мировоззрение 1988 - Традиционное мировоззрение тюрков Южной Сибири. Пространство и время. Вещный мир / отв. ред. И. Н. Гемуев; Э. Л. Львова, И. В. Октябрьская, А. М. Сагалаев, М. С. Усманова. Новосибирск: Наука, Сиб. отделение, 1988. $225 \mathrm{c}$.

Шатинова 1981 - Шатинова Н. И. Семья у алтайцев. Горно-Алтайск: Горно-Алт. отд. Алтайского кн. изд-ва, 1981.183 с.

Швецов 1900 - Швецов С. П. Горный Алтай и его население: [в 4 т.] / Статистический отдел при Главном управлении Алтайско- 
го округа. Т. 1: Кочевники Бийского уезда / составил С. П. Швецов. Вып. 1. Барнаул: Типо-лит. Гл. упр. Алт. округа, 1900. 447 с.

Эбель, Трифанова, Константинов 2018 Эбель А. В., Трифанова С. В., Константинов H. A. Культура населения Алтая эпохи древности и средневековья: проблемы ре-

\section{References}

Babrasheva T. K., Bokonokova A. N. (comps.) Mysteries of Altaian National Clothes. GornoAltaysk: Enchi, 2010. 56 p. (In Russ.)

Bichurin N. Ya. Compendium of Notes on Peoples to Have Inhabited Central Asia in Ancient Times. Part I. St. Petersburg: Printing House of Military Schools, 1851.484 p. (In Russ.)

Bunge A. Travelling across the Eastern Altay Mountains. In: Bedyurov B. (comp.) A Word about the Altay. Book III. Part I: Agriculture, Flora and Fauna, Ethnography, Religion, History. Gorno-Altaysk: Yuch-SyumerBelukha, 2004. Pp. 241-369. (In Russ.)

Ebel A. V., Trifanova S. V., Konstantinov N. A. Culture of Ancient and Medieval Population of the Altay: Problems of Reconstruction, and Comparative Insights into Traditional Culture of the Altaians. N. Tadysheva (ed.). Surazakov Institute for Altaic Studies. Gorno-Altaysk, 2018. 120 p. Available at: http://www.niialt.ru/ nauchnye-trudy/93-izdaniya-2020 (accessed: October 22, 2020). (In Russ.)

Ekeev N. V., Ekeeva N. M., Enchinov E. V. (eds.) The Altaians: Ethnic History, Traditional Culture, Contemporary Development. Surazakov Institute for Altaic Studies. Gorno-Altaysk: Gorno-Altayskaya Tipografiya, 2014. 464 p. (In Russ.)

Funk D. A., Tomilov N. A. (eds.) Siberian Turks. Miklouho-Maclay Institute of Ethnology and Anthropology (RAS); Institute of Archaeology and Ethnography (Omsk Office, Sib. Branch of RAS). Moscow: Nauka, 2006. 678 p. (In Russ.)

Gemuev I. N. et al. (eds.) Traditional Worldviews of South Siberian Turks: The World of Things. Novosibirsk: Nauka, 1988. 225 p. (In Russ.)

Kichekova B. Yu. Exploring Altaian traditional clothes and decorative/applied arts. In: Bilim. Vol. 5. Gorno-Altaysk: Surazakov Institute for Altaic Studies, 2009. Pp. 126-130. (In Russ.)

Kichekova B. Yu. Exploring Altaian traditional clothes and decorative/applied arts. Bilim конструкции и сопоставления с традиционной культурой алтайцев [электронный ресурс] / ред. Н. О. Тадышева. Горно-Алтайск, 2018. 120 c. URL: http://www.niialt.ru/ nauchnye-trudy/93-izdaniya-2020 (дата обращения: 22.10.2020).

(scientific journal). 2010. Vol. 6. Pp. 126-130. (In Russ.)

Kichekova B. Yu. Traditional garments of Altaians. In: Mayzina A. N. (ed.) Bilim. Vol. 4. GornoAltaysk: Surazakov Institute for Altaic Studies, 2008. Pp. 165-172. (In Russ.)

Klyueva N. I. Plait decorative elements of Siberian peoples. In: Material and Spiritual Culture of Siberia. Collected Papers by the Museum of Anthropology and Ethnography. Vol. XLII. Leningrad: Nauka, 1988. Pp. 105-128. (In Russ.)

Ledebur K. F. Travelling across Mountains and Foothills of the Altay. In: Bedyurov B. (comp.) A Word about the Altay. Book III. GornoAltaysk: Yuch-Syumer-Belukha, 2004. Pp. 59240. (In Russ.)

Potapov L. P. Clothes of Altaians. In: Collected Papers by the Museum of Anthropology and Ethnography. Vol. 13. Moscow; Leningrad: USSR Academy of Sciences, 1951. Pp. 5-59. (In Russ.)

Radlov V. V. From Siberia: Pages of the Diary. Moscow: Nauka, 1989. 749 p. (In Russ.)

Shatinova N. I. The Altaians: Family. GornoAltaysk: Altay Book Publ. (Gorno-Altaysk Branch), 1981. 183 p. (In Russ.)

Shvetsov S. P. (comp.) The Altai Mountains and Their Heritage. In 4 vols. Vol. 1: Nomads of Biysk Uyezd. Part 1. Barnaul: Executive Office of Altay Okrug, 1900. 447 p. (In Russ.)

Spassky G. Teleuts: or the White Kalmyks. In: Bedyurov B. (comp.) A Word about the Altay. Book III. Part I. Gorno-Altaysk: Yuch-SyumerBelukha, 2004. Pp. 33-42. (In Russ.)

Tadina N. A. Altaian Wedding Rites, $19^{\text {th }}-20^{\text {th }}$ Centuries. Gorno-Altaysk: Yuch-Syumer, 1995. 207 p. (In Russ.)

Tokhtonova M. M. Traditions of women's garments. Azhuda. 2004. No. 1. Pp. 4-6. (In Russ.)

Zaytseva E. P. (comp.) Altaian Folk Costume. Gorno-Altaysk: Altay Book Publ. (GornoAltaysk Branch), 1990. 96 p. (In Russ.) 